\title{
Hippocampal cGMP-Dependent Protein Kinase I Supports an Age- and Protein Synthesis-Dependent Component of Long-Term Potentiation But Is Not Essential for Spatial Reference and Contextual Memory
}

\author{
Thomas Kleppisch, ${ }^{1}$ Wiebke Wolfsgruber, ${ }^{1}$ Susanne Feil, ${ }^{1}$ Rüdiger Allmann, ${ }^{1}$ Carsten T. Wotjak, ${ }^{2}$ Sandra Goebbels, ${ }^{3}$ \\ Klaus-Armin Nave, ${ }^{3}$ Franz Hofmann, ${ }^{1}$ and Robert Feil ${ }^{1}$ \\ ${ }^{1}$ Institut für Pharmakologie und Toxikologie, 80802 München, Germany, ${ }^{2}$ Max-Planck-Institut für Psychiatrie, 80804 München, Germany, and ${ }^{3}$ Max- \\ Planck-Institut für Experimentelle Medizin, 37075 Göttingen, Germany
}

cGMP-dependent protein kinase I (cGKI) is expressed in the hippocampus, but its role in hippocampal long-term potentiation (LTP) is controversial. In addition, whether cGKI is involved in spatial learning has not been investigated. To address these issues, we generated mice with a hippocampus-specific deletion of cGKI (cGKI ${ }^{\mathrm{hko}}$ mice). Unlike conventional cGKI knock-out mice, $\mathrm{cGKI}^{\mathrm{hko}}$ mice lack gastrointestinal and cardiovascular phenotypes and have a normal life expectancy, which enables us to analyze hippocampal synaptic plasticity and learning in young and adult animals. Hippocampal LTP after repetitive episodes of theta burst stimulation was impaired in adult (12-14 weeks of age) but not in juvenile (3- 4 weeks of age) $\mathrm{cGKI}^{\mathrm{hko}}$ mice. The difference in LTP between adult control and cGKI ${ }^{\mathrm{hko}}$ mice was abolished by the protein synthesis inhibitor anisomycin, suggesting that the impairment of LTP in adult cGKI ${ }^{\mathrm{hko}}$ mice reflects a defect in late-phase LTP. Despite their deficit in LTP, adult cGKI ${ }^{\text {hko }}$ mutants showed normal performance in a discriminatory water maze and had intact contextual fear conditioning. These results suggest that hippocampal cGKI supports an age- and protein synthesisdependent form of hippocampal LTP, whereas it is dispensable for hippocampus-dependent spatial reference and contextual memory.

Key words: cGMP-kinase; conditional knockout; Cre recombinase; long-term potentiation; hippocampus; spatial learning; fear conditioning

\begin{abstract}
Introduction
In vertebrates, two genes encoding cGMP-dependent protein kinases (cGKs), cGKI and cGKII, are known (Wernet et al., 1989; Uhler, 1993). Although the expression level of cGKII in the hippocampus is marginal, cGKI is well expressed throughout all cellular layers of the hippocampal formation (el-Husseini et al., 1995; Kleppisch et al., 1999; de Vente et al., 2001). The functional significance of hippocampal cGKI yet remains essentially unknown. Nitric oxide (NO) has been shown to act as a retrograde messenger during the induction of long-term potentiation (LTP) of synaptic transmission (Bohme et al., 1991; Schuman and Madison, 1991; Arancio et al., 1996; Kantor et al., 1996; Son et al., 1996; Wilson et al., 1999). There is some evidence that NO mediates its effect in the presynaptic neuron via (1) activation of soluble guanylyl cyclase, (2) an increase of the cytosolic cGMP concentration, and (3) activation of cGK (Zhuo et al., 1994; Arancio et al., 1995; Boulton et al., 1995). A recent analysis of synaptic transmission in cultures of hippocampal pyramidal cells further demonstrated that infusion of purified cGKI protein into
\end{abstract}

\footnotetext{
Received Dec. 9, 2002; revised April 1, 2003; accepted April 4, 2003.

This research was supported by the Deutsche Forschungsgemeinschaft and VolkswagenStiftung. We thank Sabine Brummer and Anne-Marie Ebner for excellent technical assistance, Andreas Ludwig and Stefan Herrmann for help with in situ hybridization, and Dr. Magdalena Sauvage and Anja Mederer for advice on behavioral analysis.

Correspondence should be addressed to Dr. Thomas Kleppisch, Institut für Pharmakologie und Toxikologie, Biedersteiner Strasse 29, 80802 München, Germany. E-mail: kleppisch@ipt.med.tu-muenchen.de.

Copyright $\odot 2003$ Society for Neuroscience $\quad$ 0270-6474/03/236005-08\$15.00/0
}

the presynaptic neuron can facilitate LTP after a weak tetanus, whereas injection of a cGKI inhibitor blocked LTP (Arancio et al., 2001). However, conventional inactivation of the gene(s) for cGKI or cGKII, or both, had no effect on hippocampal LTP in mice (Kleppisch et al., 1999). Moreover, LTP in all cGK-deficient mice was partially NO dependent, indicating that this component was not supported by cGKs. The reason for these discrepant results is not obvious. We cannot exclude the possibility that the lack of cGKs during ontogenesis resulted in functional compensation. In addition, the conventional cGKI knock-out mice (cGKI $^{-1-}$ mice) showed multiple phenotypes (Pfeifer et al., 1998; Massberg et al., 1999), and most of them died within 6 weeks after birth. To overcome objections related to conventional knock-out mice, we generated hippocampus-specific cGKI knock-out mice (cGKI ${ }^{\text {hko }}$ mice) using a mouse line that expresses the Cre recombinase under the control of the NEX gene promoter (Schwab et al., 2000). The recombination pattern as defined by analysis using the ACZL "indicator" mouse of Akagi et al. (1997) suggests that NEX-Cre mice express the Cre protein prominently in hippocampal and cortical neurons. cGKI ${ }^{\text {hko }}$ mice lack the phenotypes described for $\mathrm{cGKI}^{-1-}$ mice and have a normal life expectancy, which allows the analysis of hippocampal synaptic plasticity and learning in young and adult mutants. Hippocampal LTP after repetitive episodes of theta burst stimulation (TBS) was significantly reduced in adult (12-14 weeks of age) cGKI $^{\text {hko }}$ mice but was normal in juvenile (3-4 weeks of age) $\mathrm{cGKI}^{\text {hko }}$ mice. The difference in LTP between adult control and 
$\mathrm{cGKI}^{\text {hko }}$ mice was abolished by the protein synthesis blocker anisomycin. Despite their deficit in LTP, adult CGKI ${ }^{\text {hko }}$ mice showed a normal performance in a discriminatory water maze and had intact contextual fear conditioning.

\section{Materials and Methods}

Experimental animals and detection of modified alleles. The generation of mice carrying a conditional loxP-flanked ("floxed") cGKI allele (L2) or a recombined cGKI null allele ( $\mathrm{L}-$ ) and the detection of the cGKI wildtype (+), L2, and L- alleles by PCR have been described previously (Wegener et al., 2002). To achieve the Cre-mediated conversion of the floxed L2 allele into the excised L- allele in the hippocampus, NEX-Cre transgenic mice were used (Schwab et al., 2000). In NEX-Cre mice, the Cre recombinase encoding sequence has been knocked into the endogenous NEX locus, which is well expressed in hippocampal neurons. The genotyping of these mice was performed routinely by PCR analysis of tail DNA using the primers RF112 (5' -TCTTTTTCATGTGCTCTTGG- $3^{\prime}$ ), RF113 (5'-AGAATGTGGAGTAGGGTGAC-3'), and RF114 (5'CCGCATAACCAGTGAAACAG-3'). The primers RF112 and RF113 amplify a $740 \mathrm{bp}$ fragment of the NEX wild-type allele $(+)$, whereas the primers RF112 and RF114 amplify a 503 bp fragment of the Cre knock-in allele (Cre). Mice with modified cGKI alleles were crossed with NEX-Cre mice to generate hippocampus-specific cGKI knock-out mice (cGKI ${ }^{\text {hko }}$ mice; genotype: $\mathrm{cGKI}^{\mathrm{L}-/ \mathrm{L} 2}$; $\mathrm{NEX}^{+/ \mathrm{Cre}}$ ) and control mice (genotype: $\mathrm{cGKI}^{+/ \mathrm{L} 2} ; \mathrm{NEX}^{+/ \mathrm{Cre}}$ or $\left.\mathrm{cGKI}^{\mathrm{L}-/ \mathrm{L} 2} ; \mathrm{NEX}^{+/+}\right)$. Litter-matched cGKI mutants and control mice on a mixed 129Sv/C57BL6 genetic background were used in all experiments. The genotype of the mice was always unknown to the investigator. The age of experimental animals was either 3-4 weeks (juvenile mice) or 12-14 weeks (adult mice). This study conforms to the German animal protection laws.

In situ hybridization and Western blot analysis. In situ hybridization was performed adapting a previously described protocol (Ludwig et al., 1997). Cryostat sections $(18-20 \mu \mathrm{m})$ of the brain were hybridized with a ${ }^{35}$ S-UTP-labeled cRNA probe directed against nucleotides 1136-1312 of the murine cGKI cDNA (GenBank accession number NM011160) spanning the $3^{\prime}$ region of exon 9 and exon 10 and the $5^{\prime}$ region of exon 11 . For Western blot analysis, a polyclonal rabbit antiserum detecting cGKI (Pfeifer et al., 1998) was used. Equal loading of lanes was confirmed by staining with antibodies directed against p44/42 MAP kinase (New England Biolabs).

Field EPSP recordings in hippocampal slices. Field EPSPs (fEPSPs) in the CA1 region of transverse hippocampal slices (400 $\mu \mathrm{m}$ thick) were recorded essentially as described previously (Kleppisch et al., 1999). Slices were maintained in a submersion-type recording chamber perfused (1-2 $\mathrm{ml} / \mathrm{min}$ ) with artificial CSF (ACSF; $30^{\circ} \mathrm{C}$ ) containing (in $\mathrm{mm}$ ); 10 glucose, $124 \mathrm{NaCl}, 3 \mathrm{KCl}, 1.25 \mathrm{KH}_{2} \mathrm{PO}_{4}, 26 \mathrm{NaHCO}_{3}, 2 \mathrm{MgSO}_{4}$, and $2 \mathrm{CaCl}_{2}$, bubbled with $95 \% \mathrm{O}_{2} 5 \% \mathrm{CO}_{2}$, pH 7.4. Stimuli $(100 \mu \mathrm{sec})$ were delivered via a monopolar tungsten electrode to Schaffer collaterals. Signals were recorded using ACSF-filled glass pipettes (resistance $\sim 8 \mathrm{M} \Omega$ ) and an Axoclamp 2B amplifier (Axon Instruments). Stimulation and data acquisition were controlled by PULSE software (HEKA) via an ITC-16 computer interface (Instrutech). LTP was induced by a single TBS, by a strong tetanus ( 30 pulses, three times at $100 \mathrm{~Hz}$ with a pause of $5 \mathrm{sec}$ ), and by means of three TBS episodes separated by $30 \mathrm{~min}$. An individual TBS comprised four bursts separated by $200 \mathrm{msec}$, and each consisted of four pulses at $100 \mathrm{~Hz}$. In some experiments, hippocampal slices were pretreated with ACSF containing anisomycin $(20 \mu \mathrm{M}$; Sigma, St. Louis, MO) for $40 \mathrm{~min}$ before application of the TBS.

Behavior. Mice were separated at least 2 weeks before starting the experiments and kept under an inverse $12 \mathrm{hr}$ light/dark cycle (lights off at 8:00 A.M.; fear conditioning) or normal $12 \mathrm{hr}$ light/dark cycle (lights on at 8:00 A.M.; water maze experiments).

Fear conditioning. Adult control $\left(\mathrm{cGKI}^{+/ \mathrm{L} 2} ; \mathrm{NEX}^{+/ \mathrm{Cre}} ; n=9\right)$ and cGKI $^{\text {hko }}$ mice (GKI $\left.{ }^{\mathrm{L}-/ \mathrm{L} 2} \mathrm{NEX}^{+/ \mathrm{Cre}} ; n=6\right)$ were transferred from their home cages into conditioning chambers with shock floors (MED Associates, St. Albans, VT). Three minutes later, a $20 \mathrm{sec}$ tone $(9 \mathrm{kHz}$ sine waves, $80 \mathrm{~dB}$ ) was presented that co-terminated with a scrambled electric foot shock ( $2 \mathrm{sec}, 0.7 \mathrm{~mA})$. Mice were returned to their home cages $1 \mathrm{~min}$ after the tone. The next day, mice were placed into a neutral context (Plexiglas cylinder), and a 60 sec tone was presented after a control period of $3 \mathrm{~min}$ (cued memory test). In the afternoon of this day, mice were re-exposed to the conditioning context for $3 \mathrm{~min}$ without tone presentation (contextual memory test). Videotaped sessions were analyzed offline by means of customized software assessing the duration of freezing episodes, which were defined by the absence of all movements except for respiration. Setups were cleaned thoroughly between individual trials.

Spatial learning and memory. Adult control $\left(\mathrm{cGKI}^{+/ \mathrm{L} 2} ; \mathrm{NEX}^{+/ \mathrm{Cre}}\right.$; six males and six females) and cGKI ${ }^{\text {hko }}$ mice $\left(\mathrm{GKI}^{\mathrm{L}-/ \mathrm{L} 2} ; \mathrm{NEX}^{+/ \mathrm{Cre}}\right.$; six males and six females) were habituated to the water and tested in a discriminatory water maze task (Arns et al., 1999). In this task, animals had to locate a platform that was stable and kept visible in a fixed position (correct choice). The incorrect platform in a pseudorandom position sunk when a mouse climbed. The lab environment provided distal spatial cues. Trials were terminated if a mouse failed to climb one of the platforms within $30 \mathrm{sec}$ (error of omission). In case of incorrect choice or errors of omission, animals were placed by the investigator onto the correct platform. All mice remained on this platform for $10 \mathrm{sec}$ before being returned to the home cage. Potential proximal cues (e.g., urine) were removed between trials. Learning was assessed during five initial training sessions (days 1-5). Each session included 10 trials separated by 2-4 min intermissions. Memory retention was analyzed after a $6 \mathrm{~d}$ intermission from the last training session (day 11). Whether mice used spatial cues to locate the correct platform was validated in an additional session after moving the correct platform to the opposite quadrant in the water maze (reversal, day 12). The number of correct choices, the escape latency, and the number of errors of omission were used to assess memory performance. The sensitivity of our experimental setup was tested with DBA/2Ola mice (Harlan Winkelmann; 10 males) known to have deficits in spatial learning (Arns et al., 1999). Compared with C57BL/ 6JolaHsd controls (Harlan Winkelmann; 10 males), these mice showed a significantly reduced preference for the correct platform (factor strain: $F_{(1,18)}=9.85, p=0.005$; data not shown) and a prolonged escape latency (factor strain: $F_{(1,18)}=5.20, p=0.034$; data not shown) during the training phase (day 1-5).

Analysis and statistics. Data are expressed as mean \pm SEM. For estimation of LTP, the fEPSP slope was normalized to the averaged baseline response before tetanization at time 0 . Statistical analyses were performed using ANOVA for repeated measures followed by NewmanKeuls test if appropriate or using Student's $t$ test for two independent means. Significance was accepted if $p<0.05$.

\section{Results}

\section{Hippocampus-specific deletion of cGKI}

Cre recombinase mediates the conversion of a conditional cGKI allele (L2 allele) into a cGKI null allele (L- allele) (Wegener et al., 2002). NEX mRNA is detectable in mouse embryos at embryonic day 11.5, and expression of the NEX gene reaches its maximal level between postnatal days 3 and 5 (Schwab et al., 2000). PCR analysis of genomic DNA isolated from various tissues of adult (12-14 weeks of age) mice carrying a wild-type $(+)$ and a L2 allele of the cGKI and a Cre knock-in allele under the control of the NEX gene promoter (genotype: $\mathrm{cGKI}^{+/ \mathrm{L} 2} ; \mathrm{NEX}^{+/ \mathrm{Cre}}$ ) demonstrated efficient excision of exon 10 of the cGKI gene in the hippocampus (Fig. 1A). No recombination was detected in other tissues that were examined. Cerebral expression of cGKI was further analyzed by in situ hybridization of brain slices (Fig. $1 B$ ). In adult mice carrying the cGKI alleles $\mathrm{L}-$ and L2 and a Cre knock-in allele (cGKI ${ }^{\text {hko }}$ mice, genotype: $\mathrm{cGKI}^{\mathrm{L}-/ \mathrm{L} 2} ; \mathrm{NEX}^{+/ \mathrm{Cre}}$ ), cGKI wild-type mRNA was virtually absent in the pyramidal cell layer (CA3-CA1), slightly reduced in the dentate gyrus, and not altered in the cerebellum. These results are in line with the pattern of lacZ expression observed in brain slices from "Cre indicator" mice carrying a NEX-Cre knock-in allele (Schwab et al., 2000; K. A. Nave, unpublished data). To validate the mRNA data, the expression of cGKI protein was studied by Western blot analysis 
A

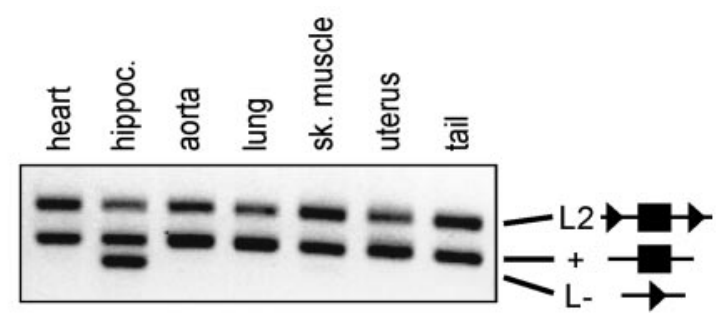

B
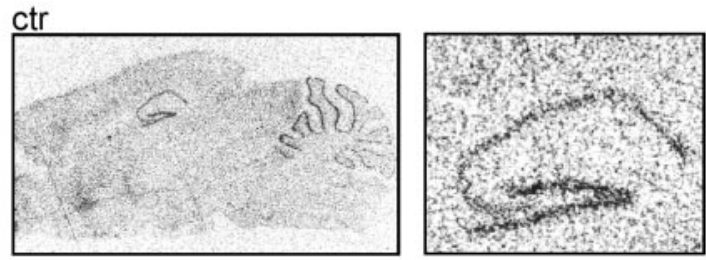

hko

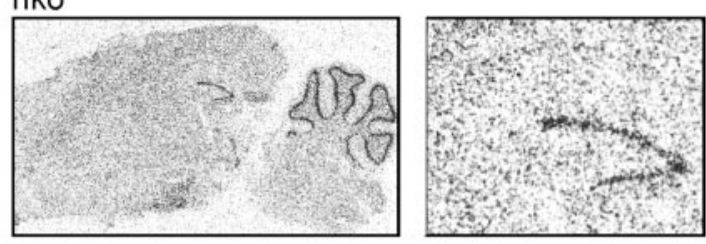

C

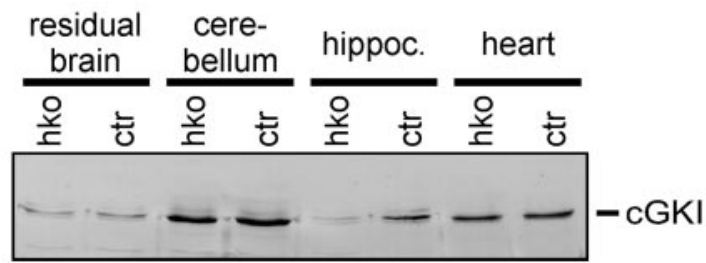

Figure 1. Conditional disruption of the CGKI gene in the hippocampus. $A, P C R$ analysis of Cre-mediated recombination. Genomic DNA isolated from the tissues indicated was used as a template. All tissue probes were obtained from adult (12-14 weeks of age) $\mathrm{CGKI}^{+/ L 2}$; NEX ${ }^{+/ / \mathrm{re}}$ mice. PCR products amplified from the $C G K I L 2$, the wild-type $(+)$, and the $L-$ allele are indicated. Boxes and triangles in the corresponding diagrams denote exon 10 of the cGKI gene and loxP sites, respectively. $B$, Analysis of CGKI mRNA expression using in situ hybridization. Sagittal brain sections of adult (12-14 weeks of age) control mice (ctr) (genotype: $\mathrm{CGKI}^{\mathrm{L}-/ \mathrm{L} 2}$; $\mathrm{NEX}^{+/+}$) and $\mathrm{CGKI}^{\text {hko }}$ mice (hko) (genotype: $\mathrm{CGKI}^{\mathrm{L}-/ \mathrm{LL}} ; \mathrm{NEX}^{+/ / \mathrm{re}}$ ) were hybridized with a labeled antisense riboprobe directed against a region of the CGKI mRNA encompassing exon 10. Right panels show the hippocampal region at a larger magnification. C, Western blot analysis of cGKI protein expression. Tissues were obtained from adult (12-14 weeks of age) control mice (ctr) (genotype: $\mathrm{CGKI}^{\mathrm{L}-/ \mathrm{LL}}$; NEX ${ }^{+/+}$) and $\mathrm{CGKI}^{\mathrm{hko}}$ mice (hko) (genotype: $\mathrm{CGKI}^{\mathrm{L}-/ \mathrm{L} 2}$; NEX ${ }^{+/ \text {(re) }}$, respectively.

of extracts from various tissues. In contrast to control mice, adult $\mathrm{cGKI}^{\text {hko }}$ mice showed a strong reduction of cGKI protein in the hippocampus, whereas protein levels in other brain regions and peripheral tissues were normal (Fig. 1C). Likewise, cGKI mRNA and protein were selectively reduced in the hippocampus of juvenile (3-4 weeks of age) mice (data not shown). The residual content of the cGKI protein in hippocampal samples from $\mathrm{cGKI}^{\text {hko }}$ mice is most likely caused by its expression in the dentate gyrus (compare Fig. $1 B$ ) and cerebral vessels (Lohmann et al., 1981). Taken together, the data demonstrate that our strategy resulted in efficient and hippocampus-specific deletion of cGKI in the $\mathrm{cGKI}^{\text {hko }}$ mice. Importantly, ${ }^{\mathrm{cGKI}}{ }^{\text {hko }}$ mice lack the gastrointestinal and cardiovascular phenotypes observed in mice with a global cGKI deficiency (Pfeifer et al., 1998; Massberg et al., 1999) and, unlike the latter, have a normal life expectancy (data not shown).
A

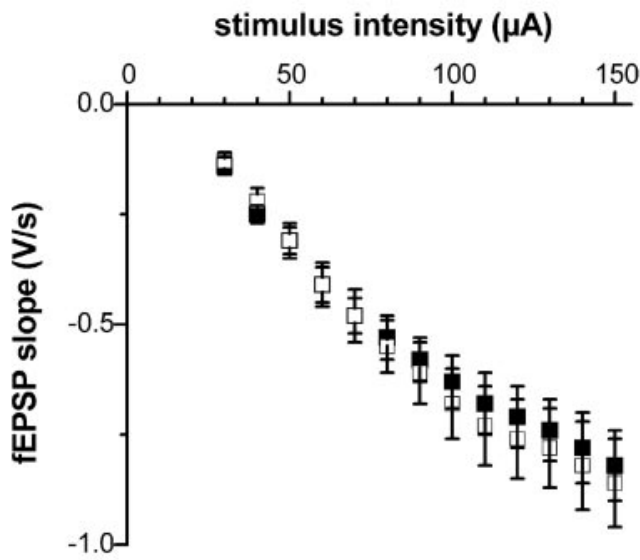

B

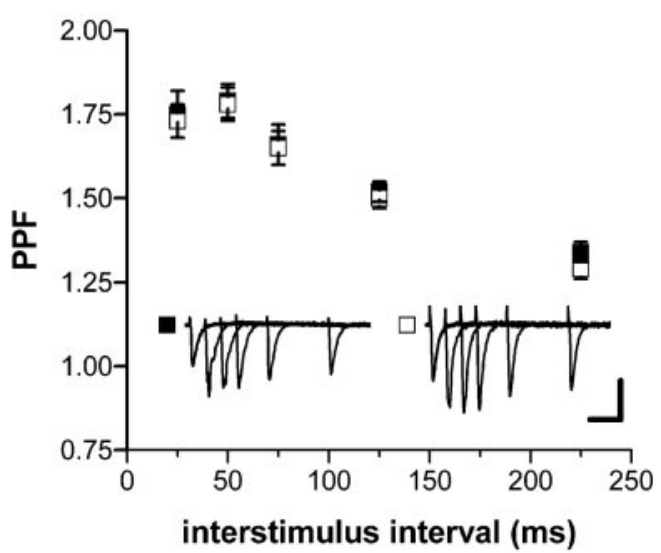

Figure 2. $\quad \mathrm{CGKI}^{\mathrm{hko}}$ mice show normal synaptic transmission. Hippocampal slices were prepared from adult (12-14 weeks of age) control ( $\square$, genotype: $\left.\mathrm{CGKI}^{+/ / 22} ; \mathrm{NEX}^{+/ / \mathrm{Cre}}\right)$ and CGKI ${ }^{\text {hko }}$ $\left(\square\right.$, genotype: $\mathrm{CGKI}^{\mathrm{L}-/ \mathrm{L} 2}$; NEX $\left.{ }^{+/ \text {(re }}\right)$ mice. fEPSPs were recorded in the CA1 region of the hippocampus after stimulation of the Schaffer collaterals. A, Input-output relation in slices from control $(n=28)$ and cGKI ${ }^{\text {hko }}(n=32)$ mice. B, Paired-pulse facilitation (PPF) in slices from control $(n=21)$ and $C G K{ }^{\text {hko }}(n=19)$ mice. Representative fEPSPs elicited by pulse pairs with interstimulus intervals of $25,50,75,125$, and 225 msec are superimposed in the corresponding insets. Calibration: $50 \mathrm{msec}, 0.5 \mathrm{mV}$.

\section{Adult cGKI ${ }^{\text {hko }}$ mice do not show a general defect in synaptic transmission}

To test for potential generalized defects in synaptic transmission caused by the gene deletion, we examined basic synaptic parameters in hippocampal slices from adult (12-14 weeks of age) control mice (genotype: $\mathrm{cGKI}^{+/ \mathrm{L} 2} ; \mathrm{NEX}^{+/ \mathrm{Cre}}$ ) and $\mathrm{cGKI}^{\text {hko }}$ mice (genotype: $\mathrm{CGKI}^{\mathrm{L}-/ \mathrm{L} 2}$; $\mathrm{NEX}^{+/ \mathrm{Cre}}$ ). The dependency of the fEPSP slope on the stimulus intensity (input-output relation) in the hippocampal CA1 region of $\mathrm{CGKI}^{\text {hko }}$ mice matched that in control mice (Fig. 2A). Moreover, there was no difference in pairedpulse facilitation observed with interpulse intervals ranging from 25 to $225 \mathrm{msec}$ in $\mathrm{cGKI}^{\text {hko }}$ and control mice (Fig. $2 \mathrm{~B}$ ). These results demonstrate that synaptic transmission was not basically altered in $\mathrm{CGKI}^{\text {hko }}$ mutants.

\section{LTP after repetitive episodes of theta burst stimulation is} reduced in adult cGKI ${ }^{\text {hko }}$ mice

We tested LTP in adult (12-14 weeks of age) cGKI $^{\text {hko }}$ mice using either a weak TBS or a strong tetanus (see Materials and Methods). In agreement with our previous study in $\mathrm{cGKI}^{-/-}$mice (Kleppisch et al., 1999), cGKI ${ }^{\text {hko }}$ mice showed normal LTP in response to a single episode of TBS (Fig. 3). The fEPSP slope $1 \mathrm{hr}$ after the TBS amounted to $119.4 \pm 6.1 \%$ (control) and $117.7 \pm$ 

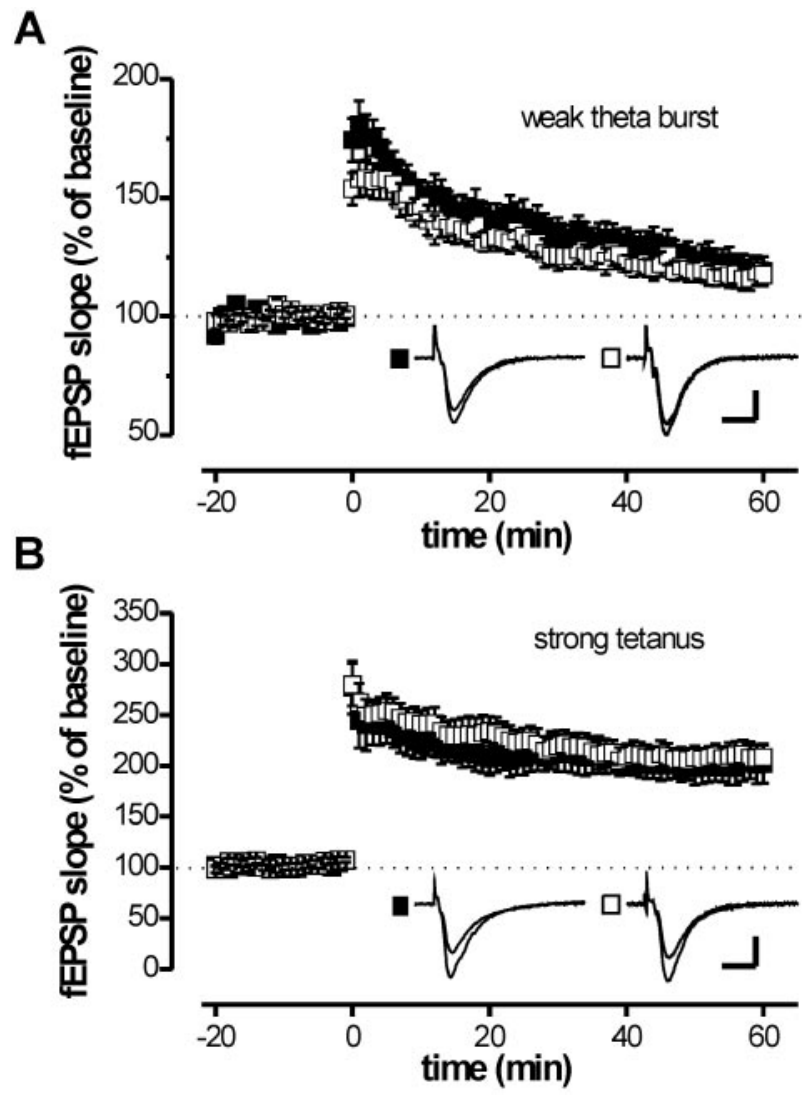

Figure 3. LTP induced by a single episode of tetanic stimulation is normal in adult CGKI ${ }^{\text {hko }}$ mice. Hippocampal slices were prepared from adult (12-14 weeks of age) control ( $\mathbf{\square}$, genotype: $\left.\mathrm{CGKI}^{+/ L 2} ; \mathrm{NEX}^{+/ / \mathrm{Cre}}\right)$ and $\mathrm{CGKI}^{\text {hko }}\left(\square\right.$, genotype: $\left.\mathrm{CGKI}^{\mathrm{L}-/ \mathrm{LL}} ; \mathrm{NEX}^{+/ / \mathrm{re}}\right)$ mice. fEPSPs were recorded in the CA1 region of the hippocampus after stimulation of the Schaffer collaterals. $A$, Time course of the fEPSP slopes after a weak theta burst ( 4 bursts each consisting of 4 pulses at $100 \mathrm{~Hz}$ with a 200 msec interburst interval). Data represent the mean \pm SEM of 14 (control) and 12 (CGKI ${ }^{\mathrm{hko}}$ ) slices. B, Time course of the fEPSP slopes after a strong tetanus ( 30 pulses 3 times at $100 \mathrm{~Hz}$ with 5 sec pause). Data represent the mean \pm SEM of 11 (control) and 9 (CGKI ${ }^{\text {hko }}$ ) slices. Representative fEPSPs recorded at times 0 (before tetanus) and 60 min after tetanus are illustrated in the corresponding insets. Calibration: $10 \mathrm{msec}, 0.5 \mathrm{mV}$.

$4.8 \%$ (cGKI $^{\text {hko }}$ ) of the fEPSP slope during baseline (Fig. $3 A$ ). Likewise, the strong tetanus induced comparable, robust LTP both in the control $(205.2 \pm 18.3 \%)$ and in $\mathrm{cGKI}^{\text {hko }}$ mice $(207.7 \pm 13.2 \%)$ (Fig. 3B). Identical results were obtained with young (3-4 weeks of age) $\mathrm{cGKI}^{\text {hko }}$ mice (data not shown). Interestingly, LTP in adult cGKI ${ }^{\text {hko }}$ mice was slightly reduced after an additional tetanus delivered $1 \mathrm{hr}$ after a TBS $(119.1 \pm 4.8 \% ; n=$ 9) compared with controls (134.7 $\pm 7.4 \% ; n=14 ; p=0.08$; data not shown). To substantiate this finding, we examined LTP in response to three episodes of TBS separated by $30 \mathrm{~min}$. As illustrated in Figure $4 A$, repetitive TBS induced cumulative LTP, which was significantly reduced in $\mathrm{CGKI}^{\text {hko }}$ mice compared with two independent control groups. Note that there was no statistically significant difference in LTP between these genotypes after the first TBS. With repetitive TBS, however, the difference in LTP between controls and $\mathrm{CGKI}^{\text {hko }}$ mice increased gradually, reaching statistical significance after the second and third TBS. One hour after the third TBS, the fEPSP slope was $174.2 \pm 9.9$ and $178.1 \pm 13.2 \%$ in the two control groups versus $133.8 \pm 9.1 \%$ in the $\mathrm{cGKI}^{\text {hko }}$ mice ( $p=0.015$ and $p=0.01$, respectively). Standard control mice carried the NEX-Cre knock-in allele $\left(\mathrm{NEX}^{+/ \mathrm{Cre}}\right)$ and an intact wild-type allele of the cGKI gene $\left(\mathrm{cGKI}^{+/ \mathrm{L} 2}\right)$. The second type of control mice, carried a L-null
A

B
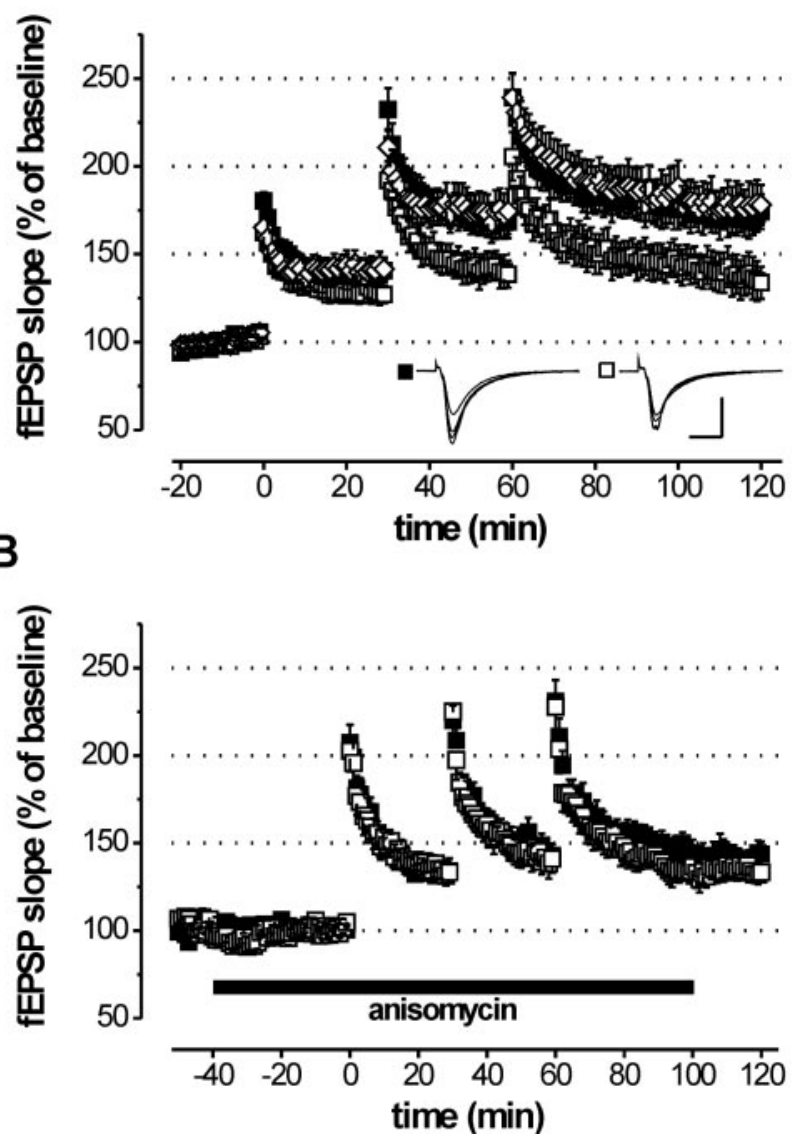

Figure 4. Adult $\mathrm{CGKI}{ }^{\mathrm{hko}}$ mice lack a translation-depending form of LTP induced by repetitive episodes of TBS. Hippocampal slices were prepared from control $\left(\square\right.$, genotype: $\mathrm{CGKI}^{+/ L 2}$. $\mathrm{NEX}^{+/ / \mathrm{rre}} ; \diamond$, genotype: $\left.\mathrm{CGKI}^{\mathrm{L}-/ \mathrm{LL}} ; \mathrm{NEX}^{+/+}\right)$and $\mathrm{CGKI}^{\mathrm{hko}}\left(\square\right.$, genotype: $\mathrm{CGKI}^{\mathrm{L}-/ \mathrm{LL} ;}$; NEX $\left.{ }^{+/ / \mathrm{re}}\right)$ mice. LTP in the Schaffer collateral pathway was induced using a stimulation protocol consisting of three episodes of TBS separated by $30 \mathrm{~min}$. A TBS comprised four bursts, each consisting of four pulses at $100 \mathrm{~Hz}$ with a $200 \mathrm{msec}$ interburst interval. $A$, Time course of the average fEPSP slope in slices from adult (12-14 weeks of age) control $(\square, n=11 ; \diamond, n=8)$ and CGKI ${ }^{\text {hko }}$ mice $(\square, n=12)$ in normal ACSF. Representative fEPSPs recorded at times 0 (before first TBS), 30, 60, and 120 min are illustrated in the corresponding insets. Calibration: $10 \mathrm{msec}, 0.5 \mathrm{mV}$. B, Time course of the average fEPSP slope in slices from adult control mice $(\square, n=9)$ and $\mathrm{GKK}^{\mathrm{hko}}$ mice $(\square, n=12)$ in the presence of anisomycin $(20 \mu \mathrm{M})$ indicated by the bar.

allele and a conditional L2 allele of the cGKI gene (cGKI $\left.{ }^{\mathrm{L}-/ \mathrm{L} 2}\right)$, but lacked the NEX-Cre knock-in allele $\left(\mathrm{NEX}^{+/+}\right)$. Because both groups of control mice showed equivalent LTP ( $p=$ 0.73 ), neither the presence of a single cGKI null allele nor the presence of the NEX-Cre knock-in allele had an effect on LTP per se. Thus, the impairment of LTP observed in adult cGKI ${ }^{\text {hko }}$ mice was caused by the ablation of cGKI in hippocampal neurons of these mice.

The component of LTP lacking in adult cGKI ${ }^{\text {hko }}$ mice depends on protein synthesis

Because the early phase of LTP (E-LTP) was not affected by a hippocampus-specific deficiency of cGKI (compare Fig. 3), we sought to explore whether the reduction of LTP after multiple TBS in $\mathrm{cGKI}^{\text {hko }}$ mice was associated with a defect of late-phase LTP (L-LTP), which can be supported by NO/cGMP signaling (Lu et al., 1999). To test for a fundamental characteristic of L-LTP, its dependence on protein synthesis, we examined LTP induced by repetitive TBS in slices incubated with the translation 


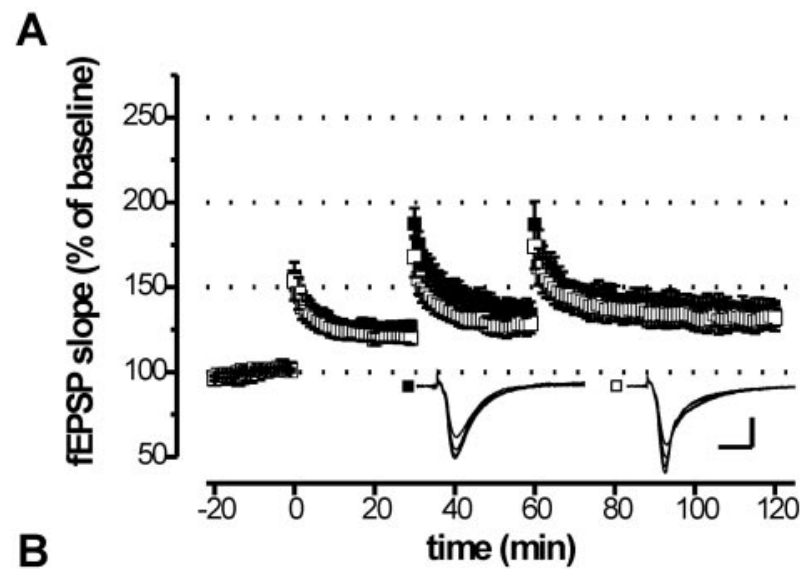

B

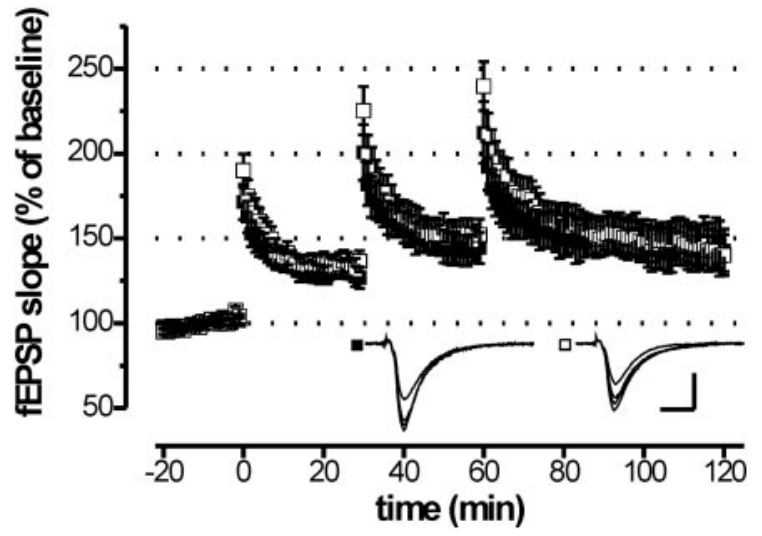

Figure 5. LTP after repetitive episodes of TBS is normal in juvenile mice with a global $\left(\right.$ (GKI $^{\mathrm{L}-/ \mathrm{L}-}$ ) or hippocampus-specific (cGKI ${ }^{\text {hko }}$ ) GGKI deficiency. Hippocampal slices were prepared from juvenile (3-4 weeks of age) mice. LTP in the Schaffer collateral pathway was induced using a stimulation protocol consisting of three episodes of TBS separated by $30 \mathrm{~min}$. A TBS comprised four bursts, each consisting of four pulses at $100 \mathrm{~Hz}$ with a $200 \mathrm{msec}$ interburst interval. $A$, Time course of the fEPSP slopes in wild-type $(\square, n=11)$ and $\mathrm{CGKI}^{\mathrm{L}-/ \mathrm{L}-}(\square, n=$ 14) mice. The corresponding fEPSP slopes $1 \mathrm{hr}$ after the third theta burst stimulation were $134.2 \pm 7.3$ and $131.9 \pm 7.6 \%$ of baseline. B, Time course of the fEPSP slopes in control ( $\square$, genotype: $\left.\mathrm{CGKI}^{+/ L 2} ; \mathrm{NEX}^{+/ / \mathrm{ree}} ; n=11\right)$ and GKI ${ }^{\mathrm{hko}}\left(\mathbf{\square}\right.$, genotype: $\mathrm{CGKL}^{\mathrm{L} / \mathrm{LL} 2} ; \mathrm{NEX}^{+/ / \mathrm{Cre}} ; n=$ 9) mice. The corresponding fEPSP slopes $1 \mathrm{hr}$ after the third theta burst stimulation were $142.9 \pm 12.5$ and $140.2 \pm 12.0 \%$ of the baseline control. Representative fEPSPs recorded at times 0 (before first tetanus), 30, 60, and 120 min are illustrated in the corresponding insets. Calibration: $10 \mathrm{msec}, 0.5 \mathrm{mV}$.

inhibitor anisomycin $(20 \mu \mathrm{M})$ for $40 \mathrm{~min}$ before application of TBS. The treatment with anisomycin, which had no effect on baseline synaptic transmission, significantly reduced LTP in control mice $(p<0.05)$ but not in cGKI ${ }^{\text {hko }}$ mice (Fig. $\left.4 A, B\right)$. Moreover, in the presence of anisomycin, LTP in control and CGKI ${ }^{\text {hko }}$ mice was no longer significantly different (Fig. $4 B$ ). The corresponding fEPSP slopes ( $1 \mathrm{hr}$ after the third TBS) in the presence of anisomycin were $141.9 \pm 6.9 \%$ (control; $n=9$ ) and $133.4 \pm$ $5.6 \%$ ( $\mathrm{cGKI}^{\text {hko }} ; n=12$ ) of baseline before TBS. Taken together, these findings indicate that LTP induced by repetitive TBS comprises a protein synthesis-dependent component that is lacking in $\mathrm{CGKI}^{\text {hko }}$ mice.

LTP after repetitive episodes of TBS is normal in juvenile cGKI-deficient mice

We further investigated whether the reduction of LTP can also be detected in juvenile (3-4 weeks of age) cGKI mutants using repetitive TBS. Hippocampal LTP induced by this protocol was normal in juvenile mice with a global (Fig. 5A) or hippocampusspecific (Fig. 5B) cGKI deficiency. Potentiation of the fEPSP slope
A

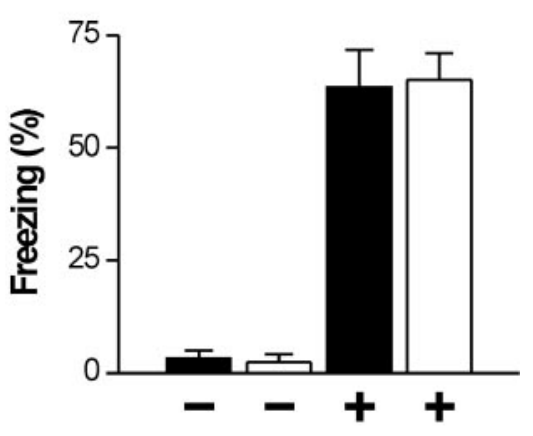

B

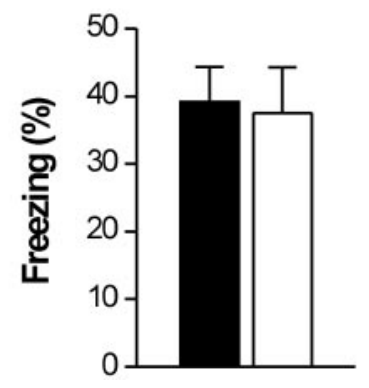

Figure 6. Adult cGKI ${ }^{\text {hko }}$ mice show intact cued and contextual fear conditioning. Adult control (filled bars, $n=9$, genotype: $\mathrm{CGKI}^{+/ 22}{ }^{\text {N NEX }}{ }^{+/ \mathrm{Cre}}$ ) and $\mathrm{CGKI}^{\text {hko }}$ mice (open bars, $n=6$, genotype: $\mathrm{GKI}^{\mathrm{L}-/ \mathrm{L} 2} \mathrm{NEX}{ }^{+/ / \mathrm{Cre}}$ ) were conditioned in special chambers by presenting a $20 \mathrm{sec}$ tone that co-terminated with an electric foot shock. Illustrated are the fractions (\%) of the total observation periods (60 sec for cued memory; $180 \mathrm{sec}$ for contextual memory) during which animals showed freezing behavior. A, Cued memory. In a neutral context, mice of either genotype showed virtually no freezing in the absence (-) of a tone and similarly strong freezing reaction during presentation of a $60 \mathrm{sec}$ tone $(+) . B$, Contextual memory. Control and CGKI ${ }^{\text {hko }}$ mice re-exposed to the conditioning context showed similar freezing responses in the absence of the conditioned stimulus (tone).

$1 \mathrm{hr}$ after the third TBS ranged from 132 to $142 \%$ and was not significantly different between cGKI mutants and their controls. In contrast to previously analyzed $\mathrm{cGKI}^{-1-}$ mice (Kleppisch et al., 1999), the global cGKI knock-out mice (cGKI ${ }^{\mathrm{L}-/ \mathrm{L}-}$ mice) used in the present study carried two null alleles devoid of any marker genes (Wegener et al., 2002). Thus, potential effects caused by the presence of a marker gene can be excluded in $\mathrm{cGKI}^{\mathrm{L}-/ \mathrm{L}-}$ mice. Taken together, the analysis of LTP in juvenile and adult cGKI-deficient mice strongly suggests an agedependent role of cGKI in hippocampal LTP induced by repetitive tetanization.

Cued and contextual fear conditioning and spatial learning is normal in adult cGKI ${ }^{\text {hko }}$ mice

Transgenic mouse models have provided evidence for the involvement of NO/cGMP-dependent signaling in various aspects of behavior (Hofmann et al., 2003). We examined the role of hippocampal cGKI in cued (hippocampus independent) and contextual (hippocampus dependent) fear conditioning. Conditioned control and cGKI ${ }^{\text {hko }}$ mice placed in a neutral context showed virtually no freezing behavior in the absence of the tone. Presentation of the tone caused a strong freezing response with no difference between control and cGKI ${ }^{\text {hko }}$ mice (Fig. 6A). Similarly, pronounced freezing was induced in both groups of mice by re-exposing them to the conditioning context, again without a difference between genotypes (Fig. 6B).

Next, we evaluated the role of hippocampal cGKI in spatial learning. There were no differences in the performance of control and $\mathrm{CGKI}^{\text {hko }}$ mice in a discriminatory water maze task, neither in 
A

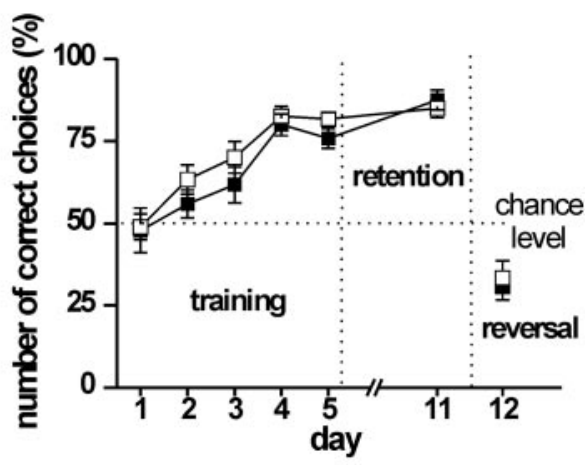

B

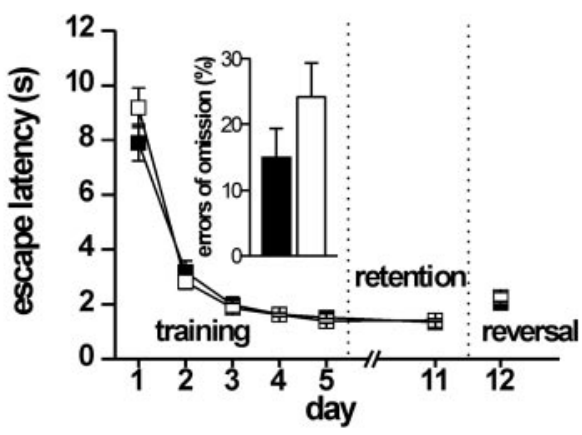

Figure 7. Adult cGKI ${ }^{\mathrm{hko}}$ mice show intact spatial learning in a discriminatory water maze task. Adult control ( $\square$ and filled bars, $n=12$, genotype: $\mathrm{CGKI}^{+/ 22}$; NEX-Cre ${ }^{+/-}$) and $\mathrm{CGKI}^{\text {hko }}$ ( $\square$ and hollow bars, $n=12$, genotype: $\mathrm{GKI}^{\mathrm{L}-/ \mathrm{L} 2}$ NEX-Cre ${ }^{+/-}$) mice had to discriminate between two visible platforms: a stable platform remaining in the same position (correct choice) and a platform in pseudorandom position that submerged when climbed by a mouse. Mice were tested over five training sessions (day 1-5) and again at day 11 (memory retention). To validate spatial learning strategies, the correct platform was then moved to the opposite quadrant (day 12). $A$, Number of correct choices expressed as the percentage of the total number of choices per session (10 trials per session corrected for the number of omissions). $B$, Time required for navigating to one of the two platforms (escape latencies). Errors of omission observed in control and CGKI ${ }^{\text {hko }}$ mice during training session at day 1 are shown in the inset.

the initial learning phase (days 1-5) nor in memory retention (Fig. 7). At day 1, the percentage of correct choices was close to chance level $(50 \%)$ in both control $(47.8 \pm 6.8 \%)$ and $\mathrm{cGKI}^{\text {hko }}$ mice $(48.9 \pm 3.9 \%)$. During the following training sessions (day 2-5), mice of either genotypes enhanced the number of correct choices to virtually identical values of $80.0 \pm 3.3 \%$ (control) and $81.7 \pm 2.1 \%$ (cGKI $^{\text {hko }}$ ) (Fig. $7 A$ ) (factor time: $F_{(4,80)}=22.5, p<$ 0.00001 ; factor genotype: $F_{(1,20)}=2.05, p=0.167$; genotype $\times$ day interaction: $\left.F_{(4,80)}=0.298 ; p=0.878\right)$ regardless of the sex of the animals (statistics not shown). Memory retention for the platform position tested $6 \mathrm{~d}$ after the last training session (day 11) was also normal in $\mathrm{cGKI}^{\text {hko }}$ mice (Fig. $7 A$ ). Subsequently, the correct platform was moved to the opposite quadrant of the water maze. During the following reversal trials (day 12), the percentage of correct choices made by control and $\mathrm{CGKI}^{\text {hko }}$ mice dropped equally to values below chance level (Fig. 7B) (statistics not shown). This indicates that mice of both genotypes relearned the novel position of the platform equally well and identified the correct platform by distal spatial cues rather than proximal cues. Except for day 1 of the training (genotype $\times$ time interaction: $F_{(4,80)}=2.85 ; p=0.028$ ), escape latencies of control and cGKI ${ }^{\text {hko }}$ mice were also not significantly different (Fig. $7 B$ ). Errors of omission occurred in both groups of mice exclusively during the first training session (day 1) without statistically significant differences in the frequency (Fig. $7 B$, inset) (statistics not shown).

\section{Discussion}

cGKI knock-out mice (cGKI ${ }^{\text {hko }}$ mice) used in the present study are characterized by (1) an efficient disruption of the cGKI gene in the hippocampus, (2) the virtual absence of cGKI mRNA in the pyramidal cell layer (CA3-CA1) of the hippopcampus, (3) a prominent reduction of the cGKI protein in extracts of the entire hippocampal formation, and (4) normal expression of cGKI in other brain regions and peripheral tissues. These data support the conclusion that $\mathrm{cGKI}^{\text {hko }}$ mice represent a model of a hippocampus-specific cGKI deficiency. Importantly, these mice do not exhibit the cardiovascular and gastrointestinal defects described for conventional $\mathrm{cGKI}^{-1-}$ mice (Pfeifer et al., 1998; Massberg et al., 1999) and have a normal life expectancy. This offered the opportunity to study LTP throughout different phases of postnatal development and to perform behavioral tests with "healthy" adult mice.

Confirming the results of a previous analysis in conventional $\mathrm{cGKI}^{-1-}$ mice (Kleppisch et al., 1999), cGKI ${ }^{\text {hko }}$ mice showed normal hippocampal LTP after a single tetanus, regardless whether a weak TBS or a strong tetanic stimulation was used. In contrast to previously described effects of cGK inhibitors on LTP (Zhuo et al., 1994; Arancio et al., 2001), these findings argue against a functional role of cGKI in E-LTP. At present, the reason for this discrepancy remains unclear because one can exclude neither nonspecific effects of cGK inhibitors nor a functional compensation in cGKI-deficient mice. Interestingly, adult cGKI $^{\text {hko }}$ mice displayed a deficit in LTP after multiple episodes of TBS (Fig. 4), indicating that cGKI might support L-LTP. Indeed, a NO/cGMP-dependent form of L-LTP has been described by Lu et al. (1999). However, it is difficult to differentiate L-LTP from E-LTP with the stimulation pattern used here (cf. Nguyen and Kandel, 1997; Hoffman et al., 2002). Remarkably, anisomycin, a protein synthesis inhibitor, significantly reduced TBS-induced LTP in adult control mice (Fig. 4). Thus, LTP induced by our stimulation protocol comprises a component showing a hallmark of L-LTP, dependence on protein synthesis (Frey et al., 1988; Barco et al., 2002). Importantly, cGKI ${ }^{\text {hko }}$ mice lacked this protein synthesis-dependent component of LTP (Fig. 4). These findings support the view that cGKI in hippocampal neurons regulates protein synthesis and L-LTP. cGK-dependent regulation of gene expression has been shown to be involved in longterm sensitization of nociception (Lewin and Walters, 1999). However, it remains unclear whether hippocampal cGKI controls translation and transcription (cf. Huber et al., 2000), e.g., via cAMP response element-binding protein phosphorylation (Lu et al., 1999; Lu and Hawkins, 2002).

The impairment of hippocampal LTP after multiple episodes of tetanization was restricted to adult (12-14 weeks of age) $\mathrm{CGKI}^{\text {hko }}$ mice. LTP was normal in juvenile (3-4 weeks of age) cGKI mutants, no matter whether the cGKI-deficiency was global or hippocampus specific. Interestingly, there was significantly more LTP in adult than in juvenile control mice $(\sim 175$ vs $\sim 135 \%)$. Moreover, LTP in adult cGKI ${ }^{\text {hko }}$ mice was reduced to $\sim 140 \%$, which was nearly identical to the LTP in juvenile control mice as well as juvenile cGKI mutants. Thus, adult control mice exhibited a fraction of LTP that was absent in adult $\mathrm{cGKI}^{\text {hko }}$ mice and all juvenile mice regardless of the genotype. This extra LTP in adult control mice likely represents a cGKI-dependent component developing during maturation to adulthood that depends on protein synthesis as discussed above. This interpretation, however, is based on the assumption that the cGKI gene is ablated early in development cGKI and the residual cGKI mRNA and protein are 
turned over completely in juvenile cGKI ${ }^{\mathrm{hko}}$ mice. It is well known that the relevance of distinct mechanisms involved in LTP can change during postnatal development, and several studies with genetically modified mice have demonstrated that the roles of particular genes in synaptic plasticity are age dependent (Ito et al., 1996; Kirkwood et al., 1997; Okabe et al., 1998; Bach et al., 1999; Dawson et al., 1999). These age-related changes are thought to correlate with alterations in the activity of specific signaling pathways or the expression of functionally important proteins (Lanahan et al., 1997; Davis et al., 2000). The expression level of hippocampal cGKI was not significantly different in juvenile and adult mice (data not shown). Hence, age-related changes in the expression of cGKI cannot explain its age-dependent role in hippocampal LTP.

Adult $\mathrm{CGKI}^{\text {hko }}$ mice showed normal performance in tests of hippocampus-dependent behavior, i.e., contextual fear conditioning and spatial learning. The deficiency of hippocampal cGKI had no effect on (1) freezing to the conditioning context, (2) acquisition of a spatial searching strategy, or (3) storage and retrieval of spatial memory. These results suggest that unlike LTP, contextual fear conditioning and spatial learning do not depend on the function of hippocampal cGKI. We cannot exclude the possibility that cGKI-dependent LTP plays a role in forms of learning and memory not tested in the present study. With regard to this, it is interesting that hippocampus-specific AMPA receptor GluR1 knock-out mice showing impaired LTP have normal spatial reference memory (water maze task) but defective spatial working memory (spontaneous alteration task) (Zamanillo et al., 1999; Reisel et al., 2002).

Mice with a global deficiency of endothelial NO synthase (eNOS) have been reported to show improved learning in the hidden-platform water maze task (Frisch et al., 2000). The present results argue against the involvement of hippocampal cGKI in the effects of eNOS-derived NO on spatial learning. It has to be emphasized that the discriminatory water maze with two visible platforms used in the present study granted fairly short escape latencies and, thus, the advantage that swim stress was significantly reduced compared with a conventional water maze task. Because NO and cGMP seem to be critical for the development of passive coping strategies in the forced swimming test (Harkin et al., 1999; Heiberg et al., 2002), superior performance of eNOS-deficient mice in the hidden-platform water maze task might reflect alterations in stress coping rather than in spatial learning. This view is also supported by the finding that eNOSdeficient mice showed normal spatial learning in a positively reinforced less stressful radial maze task (Dere et al., 2001).

In summary, our study demonstrates that hippocampal cGKI supports a protein synthesis-dependent component of LTP in adult mice but is apparently dispensable for hippocampusdependent spatial reference and contextual memory.

\section{References}

Akagi K, Sandig V, Vooijs M, Van der Valk M, Giovannini M, Strauss M, Berns A (1997) Cre-mediated somatic site-specific recombination in mice. Nucleic Acids Res 25:1766-1773.

Arancio O, Kandel ER, Hawkins RD (1995) Activity-dependent long-term enhancement of transmitter release by presynaptic $3^{\prime}, 5^{\prime}$-cyclic GMP in cultured hippocampal neurons. Nature 376:74-80.

Arancio O, Kiebler M, Lee CJ, Lev-Ram V, Tsien RY, Kandel ER, Hawkins RD (1996) Nitric oxide acts directly in the presynaptic neuron to produce long-term potentiation in cultured hippocampal neurons. Cell 87:1025-1035.

Arancio O, Antonova I, Gambaryan S, Lohmann SM, Wood JS, Lawrence DS, Hawkins RD (2001) Presynaptic role of cGMP-dependent protein kinase during long-lasting potentiation. J Neurosci 21:143-149.
Arns M, Sauvage M, Steckler T (1999) Excitotoxic hippocampal lesions disrupt allocentric spatial learning in mice: effects of strain and task demands. Behav Brain Res 106:151-164.

Bach ME, Barad M, Son H, Zhuo M, Lu YF, Shih R, Mansuy I, Hawkins RD, Kandel ER (1999) Age-related defects in spatial memory are correlated with defects in the late phase of hippocampal long-term potentiation in vitro and are attenuated by drugs that enhance the cAMP signaling pathway. Proc Natl Acad Sci USA 96:5280-5285.

Barco A, Alarcon JM, Kandel ER (2002) Expression of constitutively active CREB protein facilitates the late phase of long-term potentiation by enhancing synaptic capture. Cell 108:689-703.

Bohme GA, Bon C, Stutzmann JM, Doble A, Blanchard JC (1991) Possible involvement of nitric oxide in long-term potentiation. Eur J Pharmacol 199:379-381.

Boulton CL, Southam E, Garthwaite J (1995) Nitric oxide-dependent longterm potentiation is blocked by a specific inhibitor of soluble guanylyl cyclase. Neuroscience 69:699-703.

Davis S, Salin H, Helme-Guizon A, Dumas S, Stephan A, Corbex M, Mallet J, Laroche S (2000) Dysfunctional regulation of alphaCaMKII and syntaxin $1 \mathrm{~B}$ transcription after induction of LTP in the aged rat. Eur J Neurosci 12:3276-3282.

Dawson GR, Seabrook GR, Zheng H, Smith DW, Graham S, O’Dowd G, Bowery BJ, Boyce S, Trumbauer ME, Chen HY, Van der Ploeg LH, Sirinathsinghji DJ (1999) Age-related cognitive deficits, impaired longterm potentiation and reduction in synaptic marker density in mice lacking the beta-amyloid precursor protein. Neuroscience 90:1-13.

Dere E, Frisch C, De Souza Silva MA, Godecke A, Schrader J, Huston JP (2001) Unaltered radial maze performance and brain acetylcholine of the endothelial nitric oxide synthase knockout mouse. Neuroscience 107:561-570.

de Vente J, Asan E, Gambaryan S, Markerink-van Ittersum M, Axer H, Gallatz K, Lohmann SM, Palkovits M (2001) Localization of cGMP-dependent protein kinase type II in rat brain. Neuroscience 108:27-49.

el-Husseini AE, Bladen C, Vincent SR (1995) Molecular characterization of a type II cyclic GMP-dependent protein kinase expressed in the rat brain. J Neurochem 64:2814-2817.

Frey UA, Krug M, Reymann KG, Matthies H (1988) Anisomycin, an inhibitor of protein synthesis, blocks late phases of LTP phenomena in the hippocampal CA1 region in vitro. Brain Res 452:57-65.

Frisch C, Dere E, Silva MA, Godecke A, Schrader J, Huston JP (2000) Superior water maze performance and increase in fear-related behavior in the endothelial nitric oxide synthase-deficient mouse together with monoamine changes in cerebellum and ventral striatum. J Neurosci 20:6694-6700.

Harkin AJ, Bruce KH, Craft B, Paul IA (1999) Nitric oxide synthase inhibitors have antidepressant-like properties in mice. 1. Acute treatments are active in the forced swim test. Eur J Pharmacol 372:207-213.

Heiberg I, Wegener G, Rosenberg R (2002) Reduction of cGMP and nitric oxide has antidepressant-like effects in the forced swimming test in rats. Behav Brain Res 134:479-484.

Hoffman DA, Sprengel R, Sakmann B (2002) Molecular dissection of hippocampal theta-burst pairing potentiation. Proc Natl Acad Sci USA 99:7740-7745.

Hofmann F, Biel M, Feil R, Kleppisch T (2003) Mouse models of NO/natriuretic peptide/cGMP kinase signaling. In: Handbook of experimental pharmacology (Offermanns S, Hein L, eds). San Diego: Academic, in press.

Huber KM, Kayser MS, Bear MF (2000) Role for rapid dendritic protein synthesis in hippocampal mGluR-dependent long-term depression. Science 288:1254-1257.

Ito I, Sakimura K, Mishina M, Sugiyama H (1996) Age-dependent reduction of hippocampal LTP in mice lacking $N$-methyl-D-aspartate receptor epsilon 1 subunit. Neurosci Lett 203:69-71.

Kantor DB, Lanzrein M, Stary SJ, Sandoval GM, Smith WB, Sullivan BM, Davidson N, Schuman EM (1996) A role for endothelial NO synthase in LTP revealed by adenovirus-mediated inhibition and rescue. Science 274:1744-1748.

Kirkwood A, Silva A, Bear MF (1997) Age-dependent decrease of synaptic plasticity in the neocortex of alphaCaMKII mutant mice. Proc Natl Acad Sci USA 94:3380-3383.

Kleppisch T, Pfeifer A, Klatt P, Ruth P, Montkowski A, Fassler R, Hofmann F (1999) Long-term potentiation in the hippocampal CA1 region of mice lacking cGMP-dependent kinases is normal and susceptible to inhibition of nitric oxide synthase. J Neurosci 19:48-55. 
Lanahan A, Lyford G, Stevenson GS, Worley PF, Barnes CA (1997) Selective alteration of long-term potentiation-induced transcriptional response in hippocampus of aged, memory-impaired rats. J Neurosci 17:2876-2885.

Lewin MR, Walters ET (1999) Cyclic GMP pathway is critical for inducing long-term sensitization of nociceptive sensory neurons. Nat Neurosci 2:18-23.

Lohmann SM, Walter U, Miller PE, Greengard P, De Camilli P (1981) Immunohistochemical localization of cyclic GMP-dependent protein kinase in mammalian brain. Proc Natl Acad Sci USA 78:653-657.

Lu YF, Hawkins RD (2002) Ryanodine receptors contribute to cGMPinduced late-phase LTP and CREB phosphorylation in the hippocampus. J Neurophysiol 88:1270-1278.

Lu YF, Kandel ER, Hawkins RD (1999) Nitric oxide signaling contributes to late-phase LTP and CREB phosphorylation in the hippocampus. J Neurosci 19:10250-10261.

Ludwig A, Flockerzi V, Hofmann F (1997) Regional expression and cellular localization of the $\alpha 1$ and $\beta$ subunit of high voltage-activated calcium channels in rat brain. J Neurosci 17:1339-1349.

Massberg S, Sausbier M, Klatt P, Bauer M, Pfeifer A, Siess W, Fassler R, Ruth P, Krombach F, Hofmann F (1999) Increased adhesion and aggregation of platelets lacking cyclic guanosine $3^{\prime}, 5^{\prime}$-monophosphate kinase I. J Exp Med 189:1255-1264.

Nguyen PV, Kandel ER (1997) Brief theta-burst stimulation induces a transcription-dependent late phase of LTP requiring cAMP in area CA1 of the mouse hippocampus. Learn Mem 4:230-243.

Okabe S, Collin C, Auerbach JM, Meiri N, Bengzon J, Kennedy MB, Segal M, McKay RD (1998) Hippocampal synaptic plasticity in mice overexpressing an embryonic subunit of the NMDA receptor. J Neurosci 18:4177-4188.

Pfeifer A, Klatt P, Massberg S, Ny L, Sausbier M, Hirneiss C, Wang GX, Korth M, Aszodi A, Andersson KE, Krombach F, Mayerhofer A, Ruth P, Fassler R, Hofmann F (1998) Defective smooth muscle regulation in cGMP kinase I-deficient mice. EMBO J 17:3045-3051.
Reisel D, Bannerman DM, Schmitt WB, Deacon RM, Flint J, Borchardt T, Seeburg PH, Rawlins JN (2002) Spatial memory dissociations in mice lacking GluR1. Nat Neurosci 5:868-873.

Schuman EM, Madison DV (1991) A requirement for the intercellular messenger nitric oxide in long-term potentiation. Science 254:1503-1506.

Schwab MH, Bartholomae A, Heimrich B, Feldmeyer D, Druffel-Augustin S, Goebbels S, Naya FJ, Zhao S, Frotscher M, Tsai MJ, Nave KA (2000) Neuronal basic helix-loop-helix proteins (NEX and BETA2/Neuro D) regulate terminal granule cell differentiation in the hippocampus. J Neurosci 20:3714-3724.

Son H, Hawkins RD, Martin K, Kiebler M, Huang PL, Fishman MC, Kandel ER (1996) Long-term potentiation is reduced in mice that are doubly mutant in endothelial and neuronal nitric oxide synthase. Cell 87:1015-1023.

Uhler MD (1993) Cloning and expression of a novel cyclic GMP-dependent protein kinase from mouse brain. J Biol Chem 268:13586-13591.

Wegener JW, Nawrath H, Wolfsgruber W, Kuhbandner S, Werner C, Hof mann F, Feil R (2002) cGMP-dependent protein kinase I mediates the negative ionotropic effect of cGMP in the murine myocardium. Circ Res 90:18-20.

Wernet W, Flockerzi V, Hofmann F (1989) The cDNA of the two isoforms of bovine cGMP-dependent protein kinase. FEBS Lett 251:191-196.

Wilson RI, Godecke A, Brown RE, Schrader J, Haas HL (1999) Mice deficient in endothelial nitric oxide synthase exhibit a selective deficit in hippocampal long-term potentiation. Neuroscience 90:1157-1165.

Zamanillo D, Sprengel R, Hvalby O, Jensen V, Burnashev N, Rozov A, Kaiser KM, Koster HJ, Borchardt T, Worley P, Lubke J, Frotscher M, Kelly PH Sommer B, Andersen P, Seeburg PH, Sakmann B (1999) Importance of AMPA receptors for hippocampal synaptic plasticity but not for spatial learning. Science 284:1805-1811.

Zhuo M, Hu Y, Schultz C, Kandel ER, Hawkins RD (1994) Role of guanylyl cyclase and cGMP-dependent protein kinase in long-term potentiation. Nature 368:635-639. 